Check for updates

Cite this: RSC Adv., 2017, 7, 20259

Received 18th February 2017

Accepted 24th March 2017

DOI: 10.1039/c7ra02027a

rsc.li/rsc-advances

\section{Experimental and $a b$ initio studies of two UV nonlinear optical materials $\uparrow$}

\author{
Juanjuan Lu, ${ }^{\mathrm{ab}}$ Guoqiang Shi, ${ }^{\mathrm{ab}}$ Hongping Wu, (D) *a Ming Wen, ${ }^{\mathrm{c}}$ Dianwei Hou, ${ }^{\mathrm{a}}$ \\ Zhihua Yang, (D) ${ }^{a}$ Fangfang Zhang ${ }^{* a}$ and Shilie Pan (D) *a
}

Two new acentric polyborates, $\mathrm{Ba} 3(\mathrm{OH})\left(\mathrm{B}_{9} \mathrm{O}_{16}\right)\left[\mathrm{B}(\mathrm{OH})_{3}\right]$ and $\mathrm{Ba}_{2.16} \mathrm{~Pb}_{0.84}(\mathrm{OH})\left(\mathrm{B}_{9} \mathrm{O}_{16}\right)\left[\mathrm{B}(\mathrm{OH})_{3}\right]$ have been synthesized hydrothermally and their structures have been determined by single-crystal $\mathrm{X}$-ray diffraction. Both crystals are isostructural and crystallize in the trigonal space group P31c (no. 159). Their structures feature a three-dimensional (3D) $\mathrm{B}_{9} \mathrm{O}_{19}$ framework with 6-membered-ring tunnels, in which the $\mathrm{Ba}$ or $\mathrm{Pb} / \mathrm{Ba}$ cations and $\left[\mathrm{B}(\mathrm{OH})_{3}\right]$ groups reside. Powder second-harmonic-generation ( $\mathrm{SHG}$ ) measurements reveal that $\mathrm{Ba}_{3}(\mathrm{OH})\left(\mathrm{B}_{9} \mathrm{O}_{16}\right)\left[\mathrm{B}(\mathrm{OH})_{3}\right]$ and $\mathrm{Ba}_{2.16} \mathrm{~Pb}_{0.84}(\mathrm{OH})\left(\mathrm{B}_{9} \mathrm{O}_{16}\right)\left[\mathrm{B}(\mathrm{OH})_{3}\right]$ are type-I phase-matchable, with SHG responses of $1.1 \times$ and $1.2 \times \mathrm{KH}_{2} \mathrm{PO}_{4}$, respectively. UV-Vis-NIR diffuse reflectance analysis indicates that $\mathrm{Ba}_{3}(\mathrm{OH})\left(\mathrm{B}_{9} \mathrm{O}_{16}\right)\left[\mathrm{B}(\mathrm{OH})_{3}\right]$ and $\mathrm{Pb}_{0.29} \mathrm{Ba}_{2.71}(\mathrm{OH})\left(\mathrm{B}_{9} \mathrm{O}_{16}\right)\left[\mathrm{B}(\mathrm{OH})_{3}\right]$ have band gaps of 5.11 and $4.65 \mathrm{eV}$, respectively. In addition, first-principles calculations were employed to elucidate the origin of the NLO properties and the relationship of structure-properties.

\section{Introduction}

Nonlinear optical (NLO) materials have numerous important applications in semiconductor photolithography, laser micromachining, photochemical synthesis, and material processing due to their abilities to expand the frequency range of solidstate lasers from UV to IR. ${ }^{1,2}$ Over the past decades, extensive efforts have been made to search for new NLO materials with excellent properties, including a large second harmonic generation (SHG) response and wide transparency window, ${ }^{3}$ etc. To enhance the SHG response of the materials, "distortable" metal cations containing the $\mathrm{d}^{0}$ or $\mathrm{d}^{10}$ transition metals (e.g., $\mathrm{Ti}^{4+}, \mathrm{V}^{5+}$, $\mathrm{Zn}^{2+}, \mathrm{Cd}^{2+}, e t c$.) and stereochemically active lone pair (SCALP) cations $\left(\mathrm{Bi}^{3+}, \mathrm{Pb}^{2+}, \mathrm{Te}^{4+}\right.$, etc. $)$ are introduced into the crystal

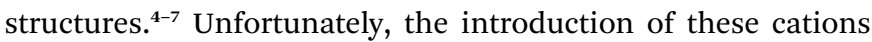
always causes red shifts of the ultraviolet (UV) absorption edge. Compared with the $\mathrm{d}^{0}$ or $\mathrm{d}^{10}$ transition metal, alkaline-earth metal cations have wide transmittances in UV region. In addition, borate is transparent in UV range as well. And it has a twice

${ }^{a}$ Key Laboratory of Functional Materials and Devices for Special Environments of CAS, Xinjiang Key Laboratory of Electronic Information Materials and Devices, Xinjiang Technical Institute of Physics \& Chemistry of CAS, 40-1 South Beijing Road, Urumqi 830011, China. E-mail: slpan@ms.xjb.ac.cn; Fax: +86-991-3838957; Tel: +86-9913674558

${ }^{b}$ University of Chinese Academy of Sciences, Beijing 100049, China

'School of Chemistry and Chemical Engineering, Harbin Institute of Technology, Harbin, Heilongjiang 150001, China

$\dagger$ Electronic supplementary information (ESI) available. CCDC 1540435-1540437. For ESI and crystallographic data in CIF or other electronic format see DOI: $10.1039 / \mathrm{c} 7 \mathrm{ra02027a}$

$\$ \mathrm{JJ}$ and GQ contributed equally. probability (in average) to be non-centrosymmetric than that of other inorganic compounds, ${ }^{1 a}$ which becomes a good candidate for NLO materials.

With this in minds, we combine the alkaline-earth metal cation with the borate system and successfully synthesize a new barium borate, $\mathrm{Ba}_{3}(\mathrm{OH})\left(\mathrm{B}_{9} \mathrm{O}_{16}\right)\left[\mathrm{B}(\mathrm{OH})_{3}\right](\mathrm{I})$, through the hydrothermal method. It has a large band gap of $5.11 \mathrm{eV}$ and is type-I phase matchable with SHG responses of about $1.1 \times \mathrm{K}_{2} \mathrm{HPO}_{4}$ (KDP). Through our investigation, barium atoms can be replaced by lead atoms to generate larger SHG response in many non-centrosymmetric structures. ${ }^{8,9}$ For instance, $\mathrm{Pb}_{2} \mathrm{Ba}_{3}\left(\mathrm{BO}_{3}\right)_{3}$ $\mathrm{Cl}$ exhibit a large SHG response $6 \times$ higher than its isomorphic compound $\mathrm{Ba}_{5}\left(\mathrm{BO}_{3}\right)_{3} \mathrm{Cl}$. Thus, we tried to substitute lead for barium in compound $\mathbf{I}$ and obtained another new compound, $\mathrm{Ba}_{2.16} \mathrm{~Pb}_{0.84}(\mathrm{OH})\left(\mathrm{B}_{9} \mathrm{O}_{16}\right)\left[\mathrm{B}(\mathrm{OH})_{3}\right](\mathrm{II})$. To systematically study the substitution influence of the $\mathrm{Pb}$ cations on optical properties, we synthesize the polycrystalline samples of $\mathrm{Pb}_{3}(\mathrm{OH})\left(\mathrm{B}_{9} \mathrm{O}_{16}\right)$ $\left[\mathrm{B}(\mathrm{OH})_{3}\right](\mathbf{I I I}),{ }^{\mathbf{1 0}}$ which is isomorphic with $\mathbf{I}$ and $\mathbf{I I}$. In this paper, we combine experimental characterization and theoretical calculations to study the optical properties among these three compounds. In addition, the thermal behavior and infrared (IR) spectra on these three compounds are also reported.

\section{Experimental}

\section{Synthesis}

All reagents were of analytical grade. Three compounds were synthesized under hydrothermal condition. The mixtures were mixed homogeneously and transferred to heat-sealed FEP Teflon pouches. The pouches were placed in $23 \mathrm{~mL}$ Teflon-lined stainless steel vessels and each vessel was added with about $8 \mathrm{~mL}$ 
distilled water. Then the vessels were heated to $210^{\circ} \mathrm{C}$ for 12 days and cooled to room temperature at a rate of $2{ }^{\circ} \mathrm{C} \mathrm{h}^{-1}$. The resulting colorless columnar crystals were obtained, washed with distilled water, and finally dried in air at ambient temperature.

Compound I. A mixture of $\mathrm{Ba}(\mathrm{OH})_{2} \cdot 8 \mathrm{H}_{2} \mathrm{O}(0.210 \mathrm{~g}, 0.67$ $\mathrm{mmol}), \mathrm{H}_{3} \mathrm{BO}_{3}(0.227 \mathrm{~g}, 3.67 \mathrm{mmol})$ and $0.1 \mathrm{~mL}$ of anhydrous ethylenediamine was mixed homogeneously. The yield of the product was just about $10 \%$ based on $\mathrm{Ba}(\mathrm{OH})_{2} \cdot 8 \mathrm{H}_{2} \mathrm{O}$. To increase the yield of compound $\mathbf{I}$, we adjusted the proportion of raw material with a mixture of $\mathrm{Ba}\left(\mathrm{NO}_{3}\right)_{2}(0.090 \mathrm{~g}, 0.34 \mathrm{mmol})$, $\mathrm{H}_{3} \mathrm{BO}_{3}(0.106 \mathrm{~g}, 1.71 \mathrm{mmol}), \mathrm{Li}(\mathrm{OH}) \cdot \mathrm{H}_{2} \mathrm{O}(0.024 \mathrm{~g}, 0.57 \mathrm{mmol})$ and $\mathrm{NH}_{4} \mathrm{NO}_{3}(0.024 \mathrm{~g}, 0.15 \mathrm{mmol})$ in deionized water. Thus the yield of the product increases to $95 \%$ based on $\mathrm{Ba}\left(\mathrm{NO}_{3}\right)_{2}$.

Compound II. A mixture of $\mathrm{BaCO}_{3}(0.099 \mathrm{~g}, 0.50 \mathrm{mmol})$, $\mathrm{H}_{3} \mathrm{BO}_{3}(0.247 \mathrm{~g}, 3.99 \mathrm{mmol}), \mathrm{Pb}\left(\mathrm{CH}_{3} \mathrm{COO}\right)_{2} \cdot 3 \mathrm{H}_{2} \mathrm{O}(0.095 \mathrm{~g}, 0.25$ $\mathrm{mmol}), \mathrm{PbF}_{2}(0.015 \mathrm{~g}, 0.06 \mathrm{mmol})$ and $0.2 \mathrm{~mL} \mathrm{NaOH}$ solution $(0.8 \mathrm{M})$ was mixed homogeneously. Colorless crystals of compound II were obtained in a yield of $85 \%$ based on $\mathrm{BaCO}_{3}$.

Compound III. A mixture of $\mathrm{PbO}(0.186 \mathrm{~g}, 0.83 \mathrm{mmol}), \mathrm{B}_{2} \mathrm{O}_{3}$ $(0.296 \mathrm{~g}, 4.25 \mathrm{mmol})$, and $0.2 \mathrm{~mL}$ of glacial acetic acid was mixed homogeneously. Colorless crystals of compound III were obtained in a yield of about $90 \%$ based on $\mathrm{PbO}$.

\section{Structural determination}

Single crystals of compounds I and II were collected at room temperature on a Bruker SMART APEX II CCD diffractometer with graphite monochromatic Mo K $\alpha$ radiation $(\lambda=0.71073 \AA)$ at 296(2) K and integrated with the SAINT program. ${ }^{11}$ The numerical absorption corrections were carried out using the SCALE program for area detector. All calculations were performed with programs from the SHELXTL crystallographic software package, ${ }^{12}$ and all of the atoms were refined using full-matrix least-squares techniques with anisotropic thermal parameters and finally converged for ${F_{0}}^{2} \geq 2 \sigma\left(F_{0}{ }^{2}\right)$. During the refinement, we found that in the structure of compound $\mathbf{I}$, the $\mathrm{Ba}(1)$ atom has a large thermal factor and a large $\mathrm{Q}$ peak is around the $\mathrm{Ba}(1)$ atom.
Refined with the split model, a $\mathrm{Ba}(1)$ site with $88.9 \%$ occupancy and a $\mathrm{Ba}(2)$ site with $11.1 \%$ occupancy converge with better $R$ values and reasonable temperature factors. The structures were checked for missing symmetry elements by the program PLATON. ${ }^{13}$ There was no higher symmetry to be found. Details of crystal parameters, data collection and structure refinements were shown in Table 1 . The atomic coordinates, equivalent isotropic displacement coefficients and important bond lengths and angels were listed in Tables S1 and S2 in the ESI, $\uparrow$ respectively. For comparison, the structure of compound III was reexamined and the data was also listed in Table 1.

Powder X-ray diffraction (XRD). Powder XRD patterns of polycrystalline sample of compounds I, II and III were obtained on a Bruker D2 PHASER diffractometer with $\mathrm{Cu} \mathrm{K} \alpha$ radiation $(\lambda$ $=1.5418 \AA$ ) at room temperature (Fig. S1 in the ESI $\dagger$ ). The $2 \theta$ range was $10-70^{\circ}$ with a step size of $0.02^{\circ}$ and a fixed counting time of $1 \mathrm{~s}$ per step.

Infrared and UV-vis-NIR spectrum measurements. The IR spectrum was recorded with a Shimadzu IR Affinity-1 Fourier transform IR spectrometer in the $400-4000 \mathrm{~cm}^{-1}$ wave number range. The samples were mixed thoroughly with dried $\mathrm{KBr}(5 \mathrm{mg}$ of each sample and $500 \mathrm{mg}$ of $\mathrm{KBr}$ ). UV-Vis-NIR diffuse reflectance spectrum was measured at room temperature on a Shimadzu SolidSpec-3700DUV spectrophotometer with a range from 190 to $2600 \mathrm{~nm}$.

\section{Thermal analysis}

The thermal gravity-differential scanning calorimetric (TG-DSC) analyses were carried out on NETZSCH STA $449{ }^{\circ} \mathrm{C}$ instrument at a temperature range of $30-1000{ }^{\circ} \mathrm{C}$ with a heating rate of $10{ }^{\circ} \mathrm{C} \mathrm{min}^{-1}$ under a constant flow of nitrogen gas.

\section{Second-order NLO measurement}

Powder SHG measurements were performed on a modified Kurtz-NLO system using a pulsed Nd:YAG laser (1064 nm, 10

Table 1 Crystal data and structure refinement results for compounds I, II and III

\begin{tabular}{|c|c|c|c|}
\hline Empirical formula & $\mathbf{I}$ & II & III \\
\hline Formula weight & 844.15 & 902.78 & 1053.70 \\
\hline Crystal system & Trigonal & Trigonal & Trigonal \\
\hline Space group, $Z$ & $P 31 c, 2$ & $P 31 c, 2$ & $P 31 c, 2$ \\
\hline \multirow[t]{2}{*}{ Unit cell dimensions } & $a=10.252(9) \AA$ & $a=10.218(8) \AA$ & $a=10.080(9) \AA$ \\
\hline & $c=8.623(3) \AA$ & $c=8.587(1) \AA$ & $c=8.533(1) \AA$ \\
\hline Volume $\left(\AA^{3}\right)$ & $785.0(3)$ & $776.3(1)$ & $751.0(1)$ \\
\hline Density (calculated) $\left(\mathrm{mg} \mathrm{m}^{-3}\right)$ & 3.571 & 3.910 & 4.642 \\
\hline Theta range for data collection (deg) & 2.29 to 27.41 & 2.30 to 27.26 & 2.33 to 27.66 \\
\hline Limiting indices & $\begin{array}{l}-13 \leq h \leq 11,-13 \leq k \leq 11 \\
-9 \leq l \leq 11\end{array}$ & $\begin{array}{l}-12 \leq h \leq 13,12 \leq k \leq 13 \\
-9 \leq l \leq 11\end{array}$ & $\begin{array}{l}-13 \leq h \leq 13,-11 \leq k \leq 13 \\
-8 \leq l \leq 11\end{array}$ \\
\hline Reflections collected/unique & $4561 / 1139[R(\mathrm{int})=0.0539]$ & $4331 / 1109[R(\mathrm{int})=0.0787]$ & $4458 / 1044[R(\mathrm{int})=0.0440]$ \\
\hline Completeness to theta & $100.0 \%$ & $100.0 \%$ & $100.0 \%$ \\
\hline Goodness-of-fit on $F^{2}$ & 1.150 & 1.071 & 1.004 \\
\hline Final $R$ indices $\left[{F_{0}}^{2}>2 \sigma\left({F_{0}}^{2}\right)\right]^{a}$ & $R_{1}=0.0457, \mathrm{w} R_{2}=0.0919$ & $R_{1}=0.0527, \mathrm{w} R_{2}=0.1155$ & $R_{1}=0.0239, \mathrm{w} R_{2}=0.0403$ \\
\hline$R$ indices (all data) ${ }^{a}$ & $R_{1}=0.0489, \mathrm{w} R_{2}=0.0931$ & $R_{1}=0.0595, \mathrm{w} R_{2}=0.1186$ & $R_{1}=0.0264, \mathrm{w} R_{2}=0.0412$ \\
\hline Extinction coefficient & $0.0018(3)$ & $0.0071(1)$ & $0.0029(2)$ \\
\hline Largest diff. peak and hole $\left(\mathrm{e} \AA^{-3}\right)$ & 1.574 and -1.404 & 1.673 and -2.123 & 1.294 and -0.759 \\
\hline
\end{tabular}

${ }^{a} R_{1}=\sum|| F_{0}|-| F_{\mathrm{c}}|| / \sum\left|F_{0}\right|$ and $\mathrm{w} R_{2}=\left[\sum \mathrm{w}\left(F_{0}{ }^{2}-{F_{\mathrm{c}}}^{2}\right)^{2} / \sum \mathrm{w} F_{0}{ }^{4}\right]^{1 / 2}$ for ${F_{0}}^{2}>2 \sigma\left(F_{0}{ }^{2}\right)$. 
$\mathrm{kHz}, 10 \mathrm{~ns}$ ). A detailed description of the methodology has been published. ${ }^{14}$ As the powder SHG efficiency has been shown to strongly depend on particle size. The crystals of three compounds were ground and sieved into distinct particle size ranges: $<20,20$ $38,38-55,55-88,88-105,105-150$, and $150-200 \mu \mathrm{m}$, respectively. The microcrystalline samples of KDP served as the standard and were also sieved into the same particle size ranges.

\section{Theoretical calculation details}

The band structure of compounds I and III have been calculated by the first principles method. For compound I, we only think that the $\mathrm{Ba}(1)$ atoms are $100 \%$ occupancy used for the calculation, while for compound II calculations were not performed since the site disorder existed in the structure. The plane-wave pseudopotential method implemented in the CASTEP package $^{15}$ was used to calculate the electronic structure and NLO properties. We adopted GGA-PBE as the exchange correlation function and norm-conserving pseudopotential to treat electron-core interactions. ${ }^{16,17}$ The kinetic energy cutoff was set as 800 and $870 \mathrm{eV}$ for compounds I and III, respectively. The outmost electrons of $\mathrm{H}, \mathrm{B}$, and $\mathrm{O}$, as well as Ba-5s $5 \mathrm{~s}^{2} 5 \mathrm{p}^{6} 6 \mathrm{~s}^{2}$ and $\mathrm{Pb}-5 \mathrm{~s}^{2} 5 \mathrm{p}^{6} 5 \mathrm{~d}^{10} 6 \mathrm{~s}^{2} 6 \mathrm{p}^{2}$, were considered to be valence electrons. The $k$-point was set as $2 \times 2 \times 2$ for compounds I and III.

At a zero frequency, the SHG coefficients were calculated using the length-gauge formalism method derived by Aversa et al. and developed by Lin and Zhang et al. ${ }^{18-20}$ The static second-order nonlinear coefficients can be ascribed to virtualelectron (VE) and virtual-hole (VH) processes,

$$
x_{\alpha \beta \gamma}^{(2)}=x_{\alpha \beta \gamma}^{(2)}(\mathrm{VE})+x_{\alpha \beta \gamma}^{(2)}(\mathrm{VH}) \text {. }
$$

Where $x_{\alpha \beta \gamma}^{(2)}(\mathrm{VE})$ and $x_{\alpha \beta \gamma}^{(2)}(\mathrm{VH})$ can be computed by the following eqn (2) and (3), respectively.

$$
\begin{aligned}
x_{\alpha \beta \gamma}^{(2)}(\mathrm{VE})= & \frac{e^{3}}{2 \hbar^{2} m^{3}} \sum_{v \mathrm{vc}} \int \frac{d^{3} k}{4 \pi^{3}} P(\alpha \beta \gamma) \operatorname{Im}\left[P_{\mathrm{cv}}{ }^{\alpha} P_{\mathrm{cc}^{\prime}}{ }^{\beta} P_{\mathrm{c}^{\prime} v}{ }^{\gamma}\right] \\
& \times\left(\frac{1}{\omega_{\mathrm{cv}}{ }^{3} \omega_{v c^{\prime}}{ }^{2}}+\frac{2}{\omega_{v c^{4}}{ }^{4} \omega_{\mathrm{c}^{\prime} v}}\right) \\
x_{\alpha \beta \gamma}^{(2)}(\mathrm{VH})= & \frac{e^{3}}{2 \hbar^{2} m^{3}} \sum_{v v^{\prime} \mathrm{c}} \int \frac{d^{3} k}{4 \pi^{3}} P(\alpha \beta \gamma) \operatorname{Im}\left[P_{v v^{\prime}}{ }^{\alpha} P_{\mathrm{cv}^{\prime}}{ }^{\beta} P_{\mathrm{cv}}{ }^{\gamma}\right] \\
& \times\left(\frac{1}{\omega_{\mathrm{cv}}{ }^{3} \omega_{v c^{\prime}}{ }^{2}}+\frac{2}{\omega_{v \mathrm{c}}{ }^{4} \omega_{\mathrm{c}^{\prime} v}}\right)
\end{aligned}
$$

here, $\alpha, \beta, \gamma$ are Cartesian components, while $v$ and $v^{\prime}$ donate valence bands (VBs), $\mathrm{c}$ and $\mathrm{c}^{\prime}$ donate conduction bands (CBs). And then $P(\alpha \beta \gamma), \hbar \omega_{i j}$ and $P_{i j}{ }^{\alpha}$ refer to full permutation, the band energy difference and momentum matrix elements, respectively.

\section{Results and discussion}

\section{Crystal structure}

The compounds I, II and III are isostructural, hence, only the structure of compound $\mathbf{I}$ is discussed as the representative. Compound I crystallizes in a trigonal crystal system with an acentric space group of $P 31 c$ (no. 159). In the asymmetric unit,

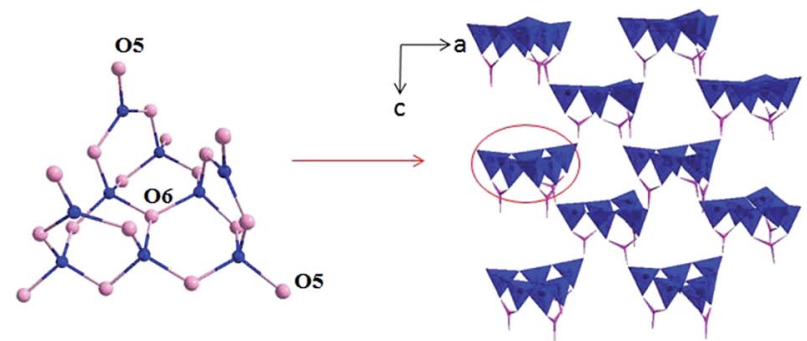

(a)

(b)

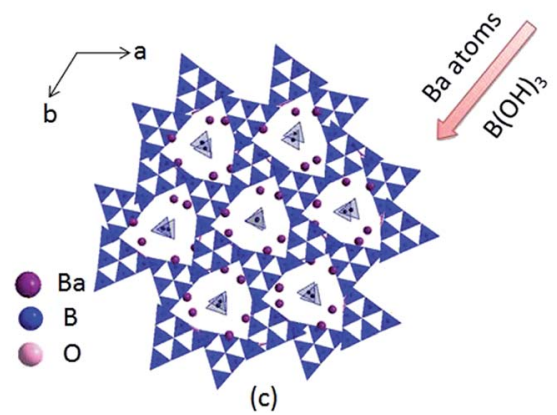

Fig. 1 Structure of compound I (the $\mathrm{Ba}-\mathrm{O}$ bonds and $\mathrm{H}$ atoms are omitted for clarity).

the $\mathrm{Ba}, \mathrm{B}$ and $\mathrm{O}$ atoms occupy one, four and eight crystallographically unique positions, respectively (Table S1 in the ESI $\dagger$ ). The $\mathrm{B}$ atoms are bonded to three or four $\mathrm{O}$ atoms to form two kinds of coordination models $\mathrm{BO}_{3}$ triangles and $\mathrm{BO}_{4}$ tetrahedra. Six $\mathrm{BO}_{4}$ tetrahedra connected with three $\mathrm{BO}_{3}$ triangles to construct $\mathrm{B}_{9} \mathrm{O}_{19}$ group (Fig. 1a), which further connected by sharing oxygen atoms to build a 3D framework with tunnels along $c$ axis (Fig. 1b), where the $\mathrm{Ba}$ atoms and $\mathrm{B}(\mathrm{OH})_{3}$ reside in (Fig. 1c).

In the structure of compound $\mathbf{I}$, the $\mathrm{Ba}$ atoms are connected with nine $\mathrm{O}$ atoms to form the $\mathrm{Ba}(1) \mathrm{O}_{9}$ polyhedra, with the $\mathrm{Ba}-\mathrm{O}$ bond lengths ranging in 2.496(3)-3.192(1) $\AA$ (average $=2.811(0)$ A). Three $\mathrm{Ba}(1) \mathrm{O}_{9}$ polyhedra connect with each other by sharing edges to form the 3D Ba-O framework (Fig. S2 in the ESI $\dagger$ ). The $\mathrm{B}-\mathrm{O}$ distances vary from 1.347(1)-1.441(1) A (average = 1.376(5) $\AA$ ) in the $\mathrm{BO}_{3}$ triangles and 1.442(1)-1.534(1) $\AA$ (average = $1.472(3) \AA)$ in the $\mathrm{BO}_{4}$ tetrahedra, respectively, which are also similar to reported values in other borates, such as $\mathrm{Ba}_{4} \mathrm{~B}_{11} \mathrm{O}_{20^{-}}$ $\mathrm{F}^{5 d} \mathrm{M}_{2} \mathrm{Ca}_{3} \mathrm{~B}_{16} \mathrm{O}_{28}(\mathrm{M}=\mathrm{Rb}, \mathrm{Cs})^{21}$ and $\mathrm{Sr}_{4} \mathrm{~B}_{10} \mathrm{O}_{18}(\mathrm{OH})_{2} \cdot 2 \mathrm{H}_{2} \mathrm{O} .{ }^{22} \mathrm{In}$ addition, the bond valences of the $\mathrm{Ba}, \mathrm{Pb}, \mathrm{B}$ and $\mathrm{O}$ atoms have been calculated according to the Brown parameters for compounds I, II and III and are listed in Table S1 in the ESI, $\dagger$ which are in agreement with their ideal oxidation state $(\mathrm{Ba},+2$; $\mathrm{Pb},+2 ; \mathrm{B},+3 ; \mathrm{O},-2)$.

Compounds I, II and III are isostructural and their fundamental structure units are all $\mathrm{B}_{9} \mathrm{O}_{19}$ group, which further connected with each other to build the 3D framework. While the coordination of the cations are not the same. In compound II, one site is occupied by constitutionally disordered $\mathrm{Pb}$ and $\mathrm{Ba}$ atoms, which is different from the total occupation of atoms on each site for compound III. In addition, in compounds $\mathbf{I}$ and $\mathbf{I I}$, the $\mathrm{Ba}$ atoms and $\mathrm{Pb} / \mathrm{Ba}$ atoms 
Table 2 Assignments of the infrared absorption peaks for compounds I, II and III

\begin{tabular}{llll}
\hline Mode description & $\mathbf{I}\left(\mathrm{cm}^{-1}\right)$ & II $\left(\mathrm{cm}^{-1}\right)$ & III $\left(\mathrm{cm}^{-1}\right)$ \\
\hline Characteristic peak of $\mathrm{OH}$ & 3007 & 3455 & 3441 \\
Asymmetric stretching of $\mathrm{B}_{3}-\mathrm{O}$ & 1433,1284 & $1424,1318,1267$ & $1432,1347,1259$ \\
Asymmetric stretching of $\mathrm{B}_{4}-\mathrm{O}$ & 1130,1060 & 1122,1056 & 1120,1056 \\
Symmetric stretching of $\mathrm{B}_{3}-\mathrm{O}$ & 925 & 939 & 950 \\
Symmetric stretching of $\mathrm{B}_{4}-\mathrm{O}$ & 803 & 815 & 810 \\
Out-of-plane bending of $\mathrm{B}_{3}-\mathrm{O}$ & $756,658,614$ & 747,664 & $743,663,601$ \\
Bending of $\mathrm{B}_{4}-\mathrm{O}$ and $\mathrm{B}_{3}-\mathrm{O}$ & 523 & 510 & 518
\end{tabular}

are both located in nine coordination environments to form the $\mathrm{Ba}(1) \mathrm{O}_{9}$ and $\mathrm{Ba} / \mathrm{PbO}_{9}$ polyhedra, respectively. While in compound III, the $\mathrm{Pb}$ atoms are located in four coordination environments to form the $\mathrm{PbO}_{4}$ tetrahedra. Then three $\mathrm{PbO}_{4}$ tetrahedra are linked by sharing $\mathrm{O}_{7}$ atoms to form isolated $\mathrm{Pb}_{3} \mathrm{O}_{10}$ unit (Fig. S1c $\dagger$ ).

\section{Thermal analysis}

The TG-DSC curves of three compounds are shown (Fig. S3†). Hydroxyl groups exist in three compounds, but at a relatively high temperature, it will be removed in the form of water molecule. Evident weight loss has been observed for compounds I, II and III in the temperature range 400-700, 400600 and $200-300{ }^{\circ} \mathrm{C}$, respectively. For compound I, the weight loss is $7.3 \%$, which is due to the release of 3.5 molecules $\mathrm{H}_{2} \mathrm{O}$ per formula unit (calculated value $7.5 \%$ ). For compound II, the weight loss of $3.9 \%$ is due to the releases of the two molecules $\mathrm{H}_{2} \mathrm{O}$ (calculated $4.0 \%$ ). While for compound III, the weight loss is $1.8 \%$ due to the release of one molecule $\mathrm{H}_{2} \mathrm{O}$ (calculated $1.7 \%)$.

\section{IR spectrum}

The IR spectra of compounds I, II and III are shown in Fig. S4. $\dagger$ Accordingly the absorption peaks are listed in Table 2. The spectra are similar on these three compounds. We can see that the absorption peaks locate at $3000-3450 \mathrm{~cm}^{-1}$ assigning to the vibrations of the $\mathrm{OH}$ groups. The strong absorption peaks between 1259 and $1433 \mathrm{~cm}^{-1}$ can be attributed to the asymmetric stretching of the $\mathrm{BO}_{3}$ groups, whereas the absorption peaks at about $925-950 \mathrm{~cm}^{-1}$ can be attributed to the symmetric stretching of the $\mathrm{BO}_{3}$ groups. The peaks located at $\sim 1120$ and $\sim 810 \mathrm{~cm}^{-1}$ are the asymmetric and symmetric stretching of the $\mathrm{BO}_{4}$ groups, respectively. The bending vibrations of the $\mathrm{BO}_{3}$ and $\mathrm{BO}_{4}$ groups can be observed in the range $510-756 \mathrm{~cm}^{-1}$. The results show that the $\mathrm{BO}_{3}$ and $\mathrm{BO}_{4}$ groups exist in the three compounds. ${ }^{23,24}$

\section{UV-Vis-NIR diffuse reflectance spectroscopy}

The optical diffuse reflectance spectra of compounds I, II and III in the region 190-2600 $\mathrm{nm}$ were measured (Fig. S5†). Reflectance spectra were converted to absorbance using the function, $F(R)=(1-R)^{2} / 2 R$, where $R$ is the reflectance and $F(R)$ is the Kubelka-Munk remission function. ${ }^{25,26}$ It is obtained that the experimental energy gaps of compounds I, II and III are 5.11, 4.65 and $4.58 \mathrm{eV}$, respectively (Fig. 2). Obviously, there is a red shift of the absorption edges from compound I to III due to the substitution of $\mathrm{Pb}$ for $\mathrm{Ba}$ atom.

The first principle calculation results show that compounds I and III are indirect band gap compounds with calculated band gap $4.76 \mathrm{eV}$ for compound I and $4.16 \mathrm{eV}$ for compound III (Fig. 3). The calculated band gaps are smaller than the experimental ones, which is mainly caused by the inaccuracy of the exchange correlation energy. ${ }^{27,28}$

To better understand the relationship between electronic structures and optical properties, the density of states (DOS) of compounds I and III were compared and shown in Fig. 4. At the valence band, the two compounds have similar electronic structures: the inner valence orbitals for the constituent ions (i.e., O-2s orbitals, B-sp mixed orbitals, Ba-4s orbitals, and $\mathrm{H}-\mathrm{s}$ orbitals), respectively. The valence bands from -10 to $0 \mathrm{eV}$ for both compounds are mainly composed of the $\mathrm{O}-2 \mathrm{p}$ orbitals, $\mathrm{B}-2 \mathrm{p}$ orbitals, Ba-4p orbitals and $\mathrm{H}$-s orbitals, respectively, and the

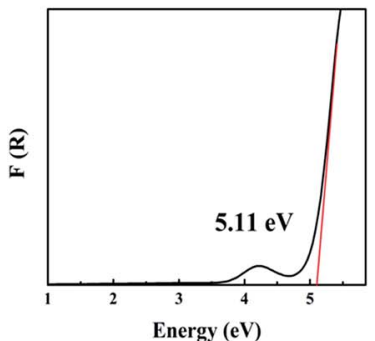

(a)

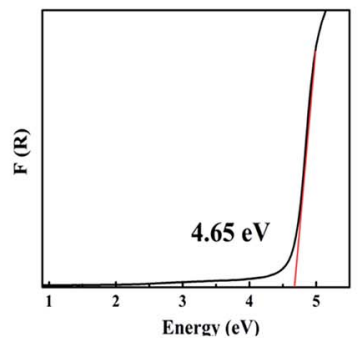

(b)

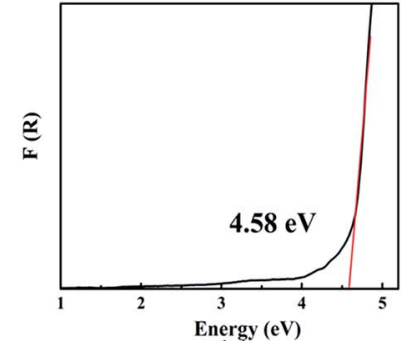

(c)

Fig. 2 The optical absorption spectra of compounds I (a), II (b) and III (c). 


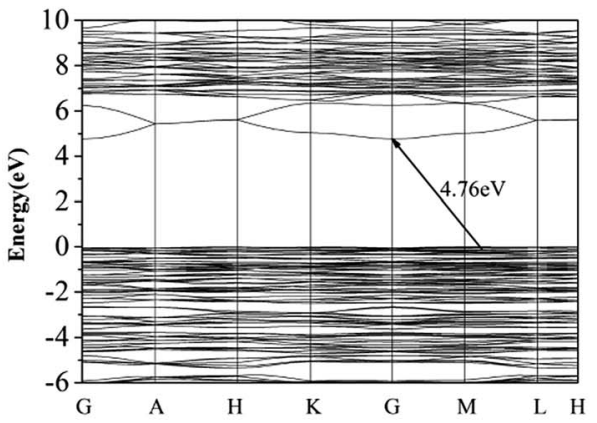

(a)

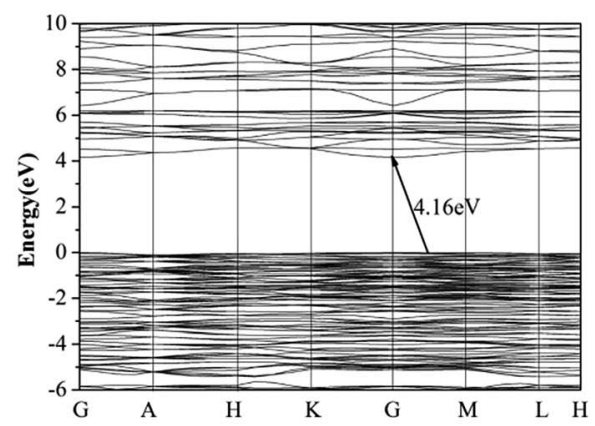

(b)

Fig. 3 The band gap of compounds I (a) and III (b).

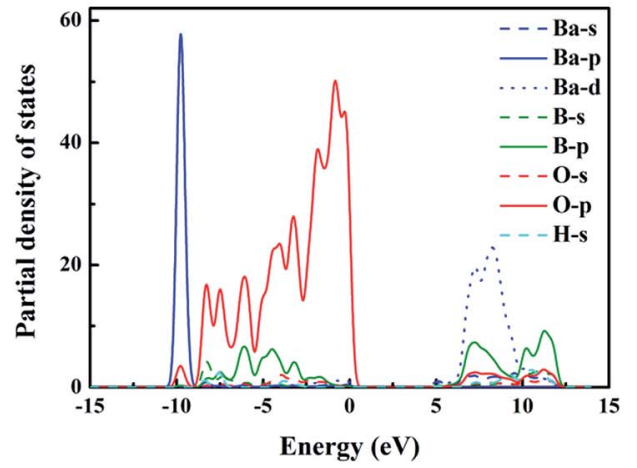

(a)

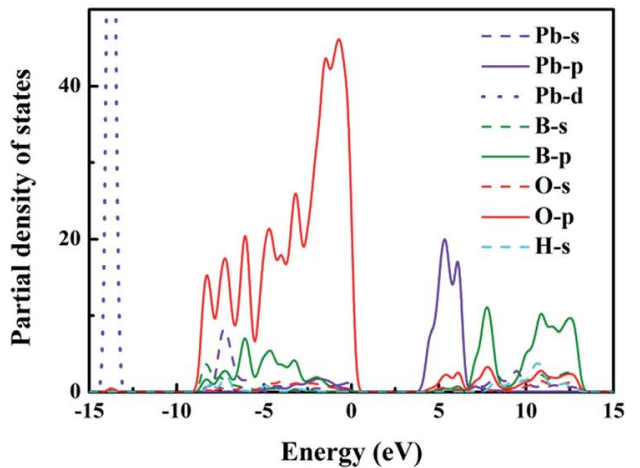

(b)

Fig. 4 The PDOS of compounds I (a) and III (b).

O-2p orbitals have dominant contribution to the maximum of the valence bands. The conduction bands are mainly composed of B$2 \mathrm{p}$ orbitals, $\mathrm{O}-2 \mathrm{p}$ orbitals and Ba-5d for compound $\mathbf{I}$, and $\mathrm{B}-2 \mathrm{p}$ orbitals, $\mathrm{O}-2 \mathrm{p}$ orbitals and $\mathrm{Pb}-6 \mathrm{p}$ for compound III. We can see that $\mathrm{Pb}-6 \mathrm{p}$ orbitals of compound III locate nearer to the Fermi level than Ba-5d orbitals of compound $\mathbf{I}$, which cause the small red shift of the band gaps from compound I to compound III.

\section{Second-harmonic generation effects}

We have also investigated their SHG responses since the title compounds belong to a NCS space group (P31c). Compounds I, II and III exhibit a SHG response of 1.1, 1.2 and 2.7 times that of KDP, respectively (Fig. 5), which indicates that the Pb substitution can enhance the SHG response in the three compounds. In addition, compounds I, II and III are all type-I phase matchable because the second-harmonic intensities increase with the increase of particle size and go to saturation values.

To visualize the SHG response of electronic states of compounds I and III, the SHG-density method ${ }^{29}$ was used to analyze the relationship between optical properties and electronic states. Since the VE and VH have the important effect on the SHG coefficient, both processes were analyzed. For compounds I and III, it crystallizes $3 m$ point group, there are three non-zero NLO coefficients. For $d_{22}$ of compound I, the contribution from the VE is $64.1 \%$ and $\mathrm{VH}$ is $35.9 \%$ (Fig. 6). In the occupied states, the $\mathrm{O}(8)-2 \mathrm{p}$ orbitals are dominant in both $\mathrm{VE}$ and $\mathrm{VH}$ processes. While in unoccupied states, the $\mathrm{O}(6)-2 \mathrm{p}$

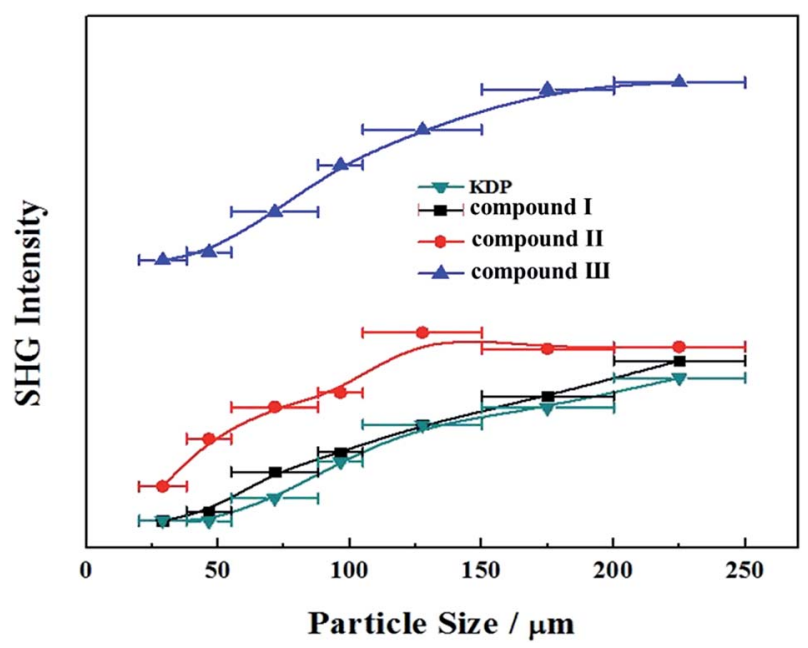

Fig. 5 Powder SHG of compounds I, II and III at $1064 \mathrm{~nm}$. Curves are drawn to guide the eye and are not a fit to the data. 


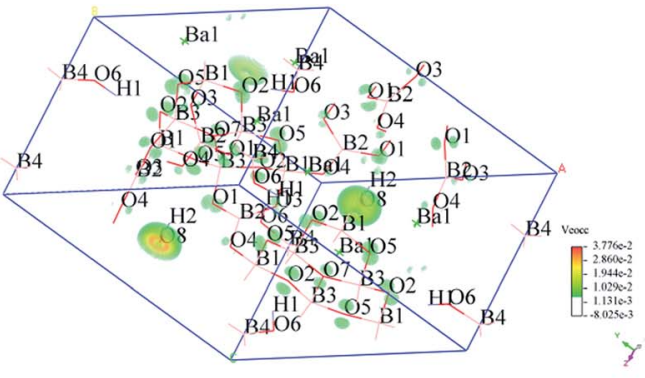

(a)

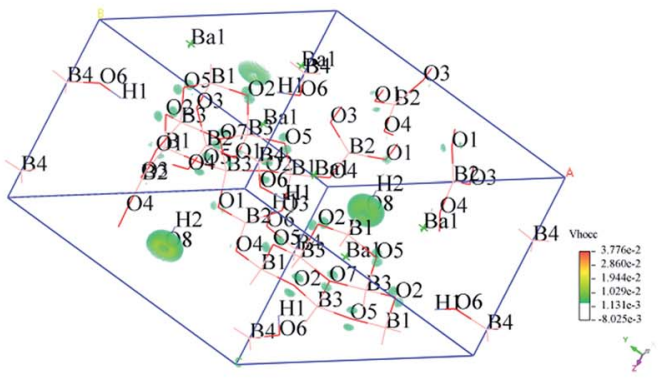

(c)

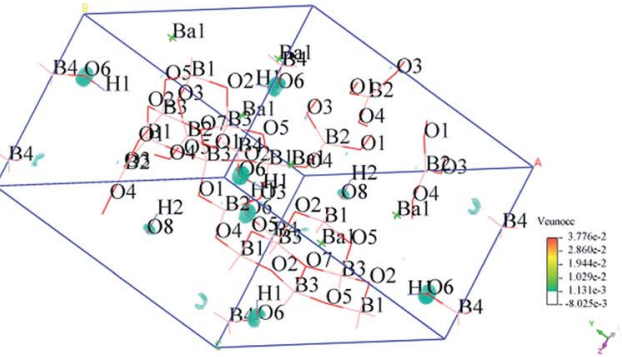

(b)

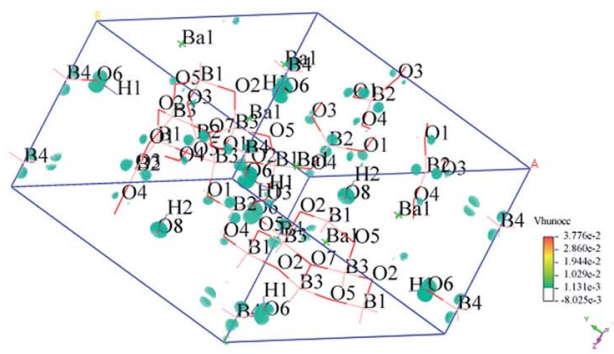

(d)

Fig. 6 SHG-weighted electron densities of the occupied and unoccupied orbitals in the VE and VH processes of compound I. (a) Occupied orbitals of VE process; (b) unoccupied orbitals of VE process; (c) occupied orbitals of VH process; (d) unoccupied orbitals of VH process.

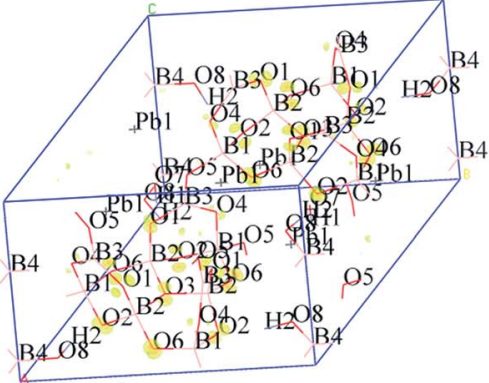

(a)

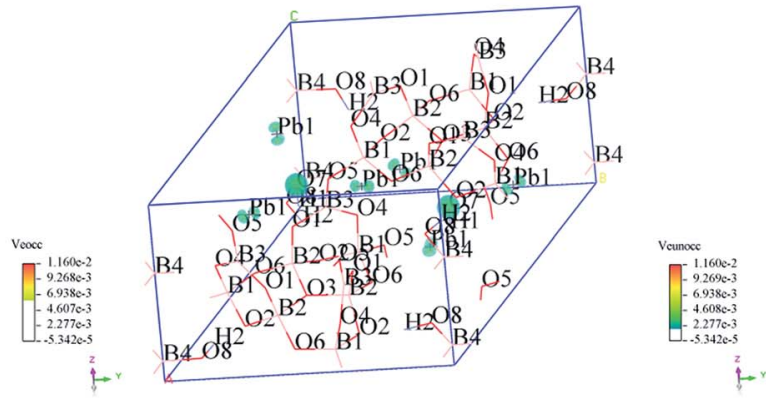

(b)

Fig. 7 SHG-weighted electron densities of the occupied and unoccupied orbitals in the VE processes of compound III. (a) Occupied orbitals of VE process; (b) unoccupied orbitals of VE process.

and $\mathrm{O}(8)-2 \mathrm{p}$ orbitals are main contributors in the VE process. The $\mathrm{B}(2)-2 \mathrm{p}$ and $\mathrm{B}(4)-2 \mathrm{p}$ orbitals play major roles in the $\mathrm{VH}$ process. Thus, the $\mathrm{B}-\mathrm{O}$ groups have the important contribution on the SHG. For compound III, VE processes are the main contributions to the $d_{22}$ SHG coefficients (Fig. 7). The analysis shows that the main contributions are $\mathrm{BO}_{3}$ groups and lead cations with stereochemically active lone pair.

\section{Conclusion}

Combining alkaline earth metal with borate, new compounds, $\mathrm{Ba}_{3}(\mathrm{OH})\left(\mathrm{B}_{9} \mathrm{O}_{16}\right)\left[\mathrm{B}(\mathrm{OH})_{3}\right]$ and $\mathrm{Pb}_{0.29} \mathrm{Ba}_{2.71}(\mathrm{OH})\left(\mathrm{B}_{9} \mathrm{O}_{16}\right)\left[\mathrm{B}(\mathrm{OH})_{3}\right]$ have been synthesized by the hydrothermal method for the first time.
Their structures feature a three-dimensional (3D) $\mathrm{B}_{9} \mathrm{O}_{19}$ framework with tunnels along $c$-direction, in which the $\mathrm{Ba}$ or $\mathrm{Pb} / \mathrm{Ba}$ cations and $\left[\mathrm{B}(\mathrm{OH})_{3}\right]$ groups dwell. $\mathrm{Ba}_{3}(\mathrm{OH})\left(\mathrm{B}_{9} \mathrm{O}_{16}\right)\left[\mathrm{B}(\mathrm{OH})_{3}\right]$, $\mathrm{Pb}_{0.29} \mathrm{Ba}_{2.71}(\mathrm{OH})\left(\mathrm{B}_{9} \mathrm{O}_{16}\right)\left[\mathrm{B}(\mathrm{OH})_{3}\right]$ and $\mathrm{Pb}_{3}(\mathrm{OH})\left(\mathrm{B}_{9} \mathrm{O}_{16}\right)\left[\mathrm{B}(\mathrm{OH})_{3}\right]$ are type-I phase-matchable, with SHG responses $1.1,1.2$ and $2.7 \times$ $\mathrm{KDP}$, respectively. The band gap of $\mathrm{Ba}_{3}(\mathrm{OH})\left(\mathrm{B}_{9} \mathrm{O}_{16}\right)\left[\mathrm{B}(\mathrm{OH})_{3}\right](5.11$ $\mathrm{eV})$ is larger than that of $\mathrm{Pb}_{3}(\mathrm{OH})\left(\mathrm{B}_{9} \mathrm{O}_{16}\right)\left[\mathrm{B}(\mathrm{OH})_{3}\right](4.65 \mathrm{eV})$. Firstprinciple calculations reveal that the bottom of conduction band of $\mathrm{Ba}_{3}(\mathrm{OH})\left(\mathrm{B}_{9} \mathrm{O}_{16}\right)\left[\mathrm{B}(\mathrm{OH})_{3}\right]$ is dominated by $\mathrm{Ba}-5 \mathrm{~d}$ orbital, while, in $\mathrm{Pb}_{3}(\mathrm{OH})\left(\mathrm{B}_{9} \mathrm{O}_{16}\right)\left[\mathrm{B}(\mathrm{OH})_{3}\right]$, the bottom of conduction band is dominated by $\mathrm{Pb}-6 \mathrm{p}$ orbital. The SHG response density shows that the $\mathrm{B}-\mathrm{O}$ groups have the important contribution to SHG response in $\mathrm{Ba}_{3}(\mathrm{OH})\left(\mathrm{B}_{9} \mathrm{O}_{16}\right)\left[\mathrm{B}(\mathrm{OH})_{3}\right]$. While the $\mathrm{BO}_{3}$ groups and 
lead cations with stereochemically active lone pair have main contribution in $\mathrm{Pb}_{3}(\mathrm{OH})\left(\mathrm{B}_{9} \mathrm{O}_{16}\right)\left[\mathrm{B}(\mathrm{OH})_{3}\right]$.

\section{Acknowledgements}

This work is supported by the Western Light Foundation of CAS (Grant 2016-QNXZ-A-2), 973 Program of China (Grant No. 2014CB648400), the National Natural Science Foundation of China (Grant No. U1303392, 51425206), the Youth Innovation Promotion Association CAS (Grant 2015353).

\section{References}

1 (a) P. Becker, Adv. Mater., 1998, 10, 979; (b) C. T. Chen, B. C. Wu, A. D. Jiang and G. M. You, Sci. Sin., Ser. B, 1985, 28, 235; (c) M. E. Hagerman and K. R. Poeppelmeier, Chem. Mater., 1995, 7, 602.

2 (a) P. G. Schunemann, P. A. Budni and K. L. Schepler, Mater. Res. Bull., 1998, 23, 45; (b) D. F. Eaton, Science, 1991, 253, 281.

3 (a) Y. C. Wu, T. Sasaki, S. Nakai, A. Yokotani, H. Tang and C. T. Chen, Appl. Phys. Lett., 1993, 62, 2614; (b) Y. Mori, I. Kuroda, S. Nakajima, T. Sasaki and S. Nakai, Appl. Phys. Lett., 1995, 67, 1818; (c) L. Cheng, J. Cryst. Growth, 1991, 110, 697; (d) A. O. Okorogu, S. B. Mirov, W. Lee, D. I. Crouthamel, N. Jenkins, A. Y. Dergachev, K. L. Vodopyanov and V. V. Badikov, Opt. Commun., 1998, 155, 307; (e) G. D. Boyd, T. J. Bridges and C. K. N. Patel, Appl. Phys. Lett., 1972, 21, 553; $(f)$ H. S. Ra, K. M. Ok and P. S. Halasyamani, J. Am. Chem. Soc., 2003, 125, 7764.

4 (a) G. H. Zhou, Z. J. Ma, K. C. Wu and N. Ye, J. Mater. Chem., 2012, 22, 19911; (b) G. H. Zou, G. Nam, H. G. Kim, H. Jo, T. S. You and K. M. Ok, RSC Adv., 2015, 5, 84754; (c) H. W. Huang, J. Y. Yao, Z. S. Lin, X. Y. Wang, R. He, W. J. Yao, N. X. Zhai and C. T. Chen, Angew. Chem., 2011, 123, 10456; (d) Y. Z. Huang, L. M. Wu, X. T. Wu, L. H. Li, L. Chen and Y. F. Zhang, J. Am. Chem. Soc., 2010, 132, 12788; (e) S. C. Wang, N. Ye, W. Li and D. Zhao, J. Am. Chem. Soc., 2010, 132, 8779.

5 (a) G. H. Zou, C. S. Lin, H. Jo, G. Nam, T. S. You and K. M. Ok, Angew. Chem., Int. Ed., 2016, 128, 12257; (b) K. Wu, Z. H. Yang and S. L. Pan, Angew. Chem., Int. Ed., 2016, 55, 6713; (c) J. L. Song, C. L. Hu, X. Xu, F. Kong and J. G. Mao, Angew. Chem., Int. Ed., 2015, 54, 3679; (d) Y. Wang and S. L. Pan, Coord. Chem. Rev., 2016, 323, 15; (e) H. P. Wu, H. W. Yu, Z. H. Yang, X. L. Hou, S. L. Pan, X. Su, K. R. Poeppelmeier and J. M. Rondinelli, J. Am. Chem. Soc., 2013, 135, 4215.

6 (a) W. L. Zhang, W. D. Cheng, H. Zhang, L. Geng, C. S. Lin and Z. Z. He, J. Am. Chem. Soc., 2010, 132, 1508; (b) H. W. Yu, S. L. Pan, H. P. Wu, W. W. Zhao, F. F. Zhang, H. Y. Li and Z. H. Yang, J. Mater. Chem., 2012, 22, 2105; (c) L. Wang, S. L. Pan, L. Chang, J. Hu and H. Yu, Inorg. Chem., 2012, 51, 1852.

7 (a) M. Wen, X. Su, H. P. Wu, J. J. Lu, Z. H. Yang and S. L. Pan, J. Phys. Chem. C, 2016, 120, 6190; (b) F. F. Zhang, F. Y. Zhang,
B. H. Lei, Z. H. Yang and S. L. Pan, J. Phys. Chem. C, 2016, 120, 12757; (c) M. Wen, Z. P. Lian, H. P. Wu, X. Su, Q. F. Yan, J. J. Lu, Z. H. Yang and S. L. Pan, RSC Adv., 2015, 5, 53448.

8 (a) X. Y. Dong, Q. Jing, Y. J. Shi, Z. H. Yang, S. L. Pan, K. R. Poeppelmeier, J. Young and J. M. Rondinelli, J. Am. Chem. Soc., 2015, 137, 9417; (b) H. Y. Li, H. P. Wu, X. Su, H. W. Yu, S. L. Pan, Z. H. Yang, Y. Lu, J. Han and K. R. Poeppelmeier, J. Mater. Chem. C, 2014, 2, 1704.

9 Z. H. Chen, S. L. Pan, Z. H. Yang, X. Y. Dong, X. Su and Y. Yang, J. Mater. Sci., 2013, 48, 2590.

10 E. L. Belokoneva, S. Y. Stefanovich, T. A. Borisova and O. V. Dimitrova, Russ. J. Inorg. Chem., 2001, 46, 1621.

11 SAINT, Version 7.60A, Bruker Analytical X-ray instruments, Inc., Madison, WI, 2008.

12 G. M. Sheldrick, SHELXTL-97 Sheldrick: Program for Crystal Structure Refinement, University of Gottingen, Germany, 1997.

13 A. L. Spek, J. Appl. Crystallogr., 2003, 36, 7.

14 L. Bohaty, Z. Kristallogr. Cryst. Mater., 1983, 164, 279.

15 S. J. Clark, M. D. Segall, C. J. Pickard, P. J. Hasnip, M. J. Probert, K. Rrfson and M. C. Payne, Z. Kristallogr., 2005, 220, 567.

16 J. P. Perdew, K. Burke and M. Ernzerhof, Phys. Rev. Lett., 1996, 77, 3865.

17 I. Varga, J. Pipek and B. Vasvári, Phys. Rev. B: Condens. Matter Mater. Phys., 1992, 46, 4978.

18 C. Aversa and J. E. Sipe, Phys. Rev. B: Condens. Matter Mater. Phys., 1995, 52, 14636.

19 J. Lin, M. H. Lee, Z. P. Liu, C. Chen and C. J. Pickard, Phys. Rev. B: Condens. Matter Mater. Phys., 1999, 60, 13380.

20 B. B. Zhang, Z. H. Yang, Y. Yang, M.-H. Lee, S. L. Pan, Q. Jing and X. Su, J. Mater. Chem. C, 2014, 2, 4133.

21 X. Y. Zhang, D. N. Li, H. P. Wu, Z. H. Yang and S. L. Pan, RSC Adv., 2016, 6, 14205.

22 F. Y. Zhang, Q. Jing, F. F. Zhang, S. L. Pan, Z. H. Yang, J. Han, M. Zhang and S. J. Han, J. Mater. Chem. C, 2014, $2,667$.

23 (a) X. F. Wang, F. F. Zhang, B. H. Lei, Z. H. Yang and S. L. Pan, $R S C A d v$. 2016, 6, 100849; (b) G. Q. Shi, F. F. Zhang, B. B. Zhang, D. W. Hou, X. L. Chen, Z. H. Yang and S. L. Pan, Inorg. Chem., 2017, 56, 344; (c) H. P. Wu, X. Su, S. J. Han, Z. H. Yang and S. L. Pan, Inorg. Chem., 2016, 55, 4806.

24 (a) Y. Yang, X. Su, S. L. Pan, M. Zhang, Y. Wang, J. Han and Z. H. Yang, CrystEngComm, 2014, 16, 1978; (b) E. L. Belokoneva, E. A. Ruchkina and O. V. Dimitrova, Russ. J. Inorg. Chem., 2001, 46, 20.

25 P. Kubelka and F. Munk, Z. Tech. Phys., 1931, 12, 593.

26 J. Tauc, Mater. Res. Bull., 1970, 5, 721.

27 M. K. Y. Chan and G. Ceder, Phys. Rev. Lett., 2010, 105, 196403.

28 J. P. Perdew and M. Levy, Phys. Rev. Lett., 1983, 51, 188. 29 C. H. Lo, Master Degree Thesis, Tamkang University, 2005. 